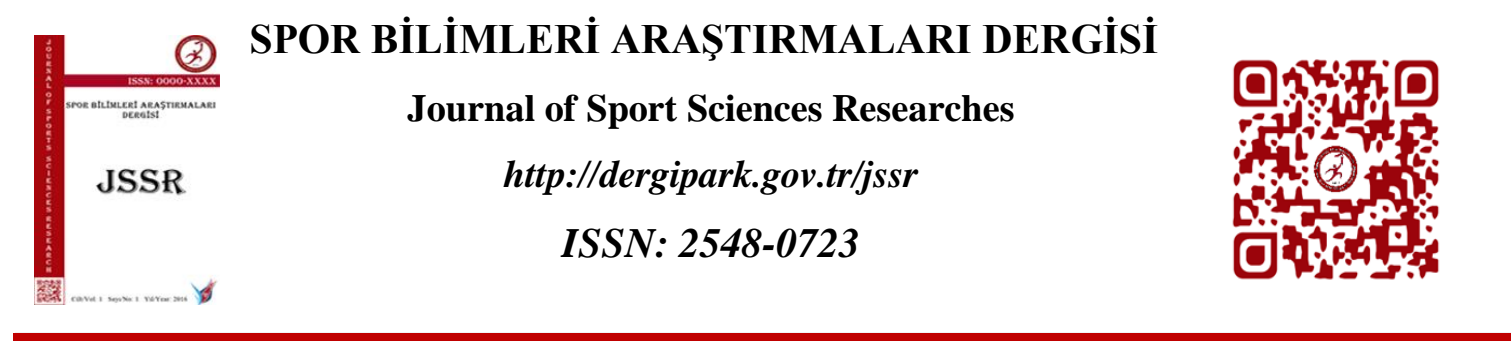

\title{
Agility Stimulators and Their Effects on Traditional Testing Protocols Case Selected Male Soccer Players
}

\author{
Mohammed Zerf ${ }^{1 *}$ \\ ${ }^{1}$ Mostaganem University, Algeria, ORCID iD: 0000-0001-5013-5446.
}

$\begin{array}{lr}\text { Abstract } & \begin{array}{r}\text { Original Article } \\ \hline \text { Baked on the theory, which advance the assessment of agility } \\ \text { performance in the real game would depend on other factors such as }\end{array} \\ \text { Visual processing, Perception and Anticipation. } & \begin{array}{r}\text { Article Info } \\ \text { Acceived: } 26.01 .2018\end{array} \\ \text { To achieve this objective, we based on 18-meter test with five } 22.06 .2018 \\ \text { delimiters spaced by } 3 \text { meters between them, proposed in two } \\ \text { situations. Situation (A), we refer to traditional agility tests, in which, } \\ \text { we change the cone with flex players. The opposite of the situation (B) } \\ \text { in which we integrate the Hexagonal Obstacle Test as part of the initial } \\ \text { protocol with five dynamic players, asked to jump in four directions }\end{array}$

*Corresponding Author: Mohammed Zerf; E-mail: biomeca.zerf@outlook.com, +213773450124 . 


\section{INTRODUCTION}

Soccer is a game that necessitates very fast body movement, which is resolute in situations within the competition such as opposing team's player with and without the ball, ball movement and teammate movement. Subsequent to these details, fast movements that become prominent in short and long sprints, explosive reactions (jump) and quick changes of direction characterize the contemporary soccer game. However, high-speed actions are recognized to influence soccer performance and can be classified into actions necessitating maximal speed, acceleration or agility (Goral, 2015). Deduce by Porcari, Bryant, \& Comana (2015) in reactive drills in comparisons with closed drills. Interpret by (Tanner \& Gore, 2012) via the training programs designed to improve agility performance type to enhance straight line or changing direction. However, Piras et al., (2014), agree that the agility includes perceptual-cognitive demands such as visual search scanning, decision making, anticipation, and reaction time that make it a separate training quality. Support in this study as much as factors of success in a real game require cognitive abilities such as reaction time associate with decision-making to coordinate movements in real time compared to changes in the environment. Reported in similar studies via top-class football players in head up and esteem of distance as the strategy to encapsulate a movement in response to a stimulus via this mental skill, according to Zerf (2016). Understand by Joyce, \& Lewindon, (2014) as a unique physical attribute that requires multiple types of strength but also cognitive abilities such as reaction time and decision-making.

Support in literature search as the ability to make calculated decisions and maneuver into position. As well as an important characteristic of team sport athletes. Its importance subjected with a growing interest in the factors that influence agility performance, as much as appropriate testing protocols and training strategies to assess and improve this quality, according to Paul, Gabbett \& Nassis, (2016). On this basis, our aims of the present study attempts to assess the difficulties of the players to coordinate their movement compared to changes in the environment. Sustained by the literature that the assessment of agility performance in team sport athletes advised that successfully in the actual game would hinge on other factors such as visual processing. In which human and/or video stimulus seems the most appropriate method to discriminate between standard of playing ability. The case of this study, whose test protocol focuses on the mobility of the 
cone as a new visual task missing in traditional field test protocols, which fixes this indispensable tool in these tests. To achieve this objective: First, we removed the impact of the ball mastery as well as all participants, was selected by attentional means, regarding their performance in 5-10-5 shuttle test. Secondly, we based on 18-meter test with five delimiters spaced by 3 meters between them, proposed in two situations. Situation (A), we refer to traditional agility tests, in which, we change the cone with flex players. The opposite of situation (B) as a new protocol, which we integrate the Hexagonal Obstacle Test as part of initial test protocol with five dynamic players, asked to jump in four directions (left- center -/ right- center -frontcenter -back) into a single rhythm, coordinated by the examiner (see protocol Figure.1).

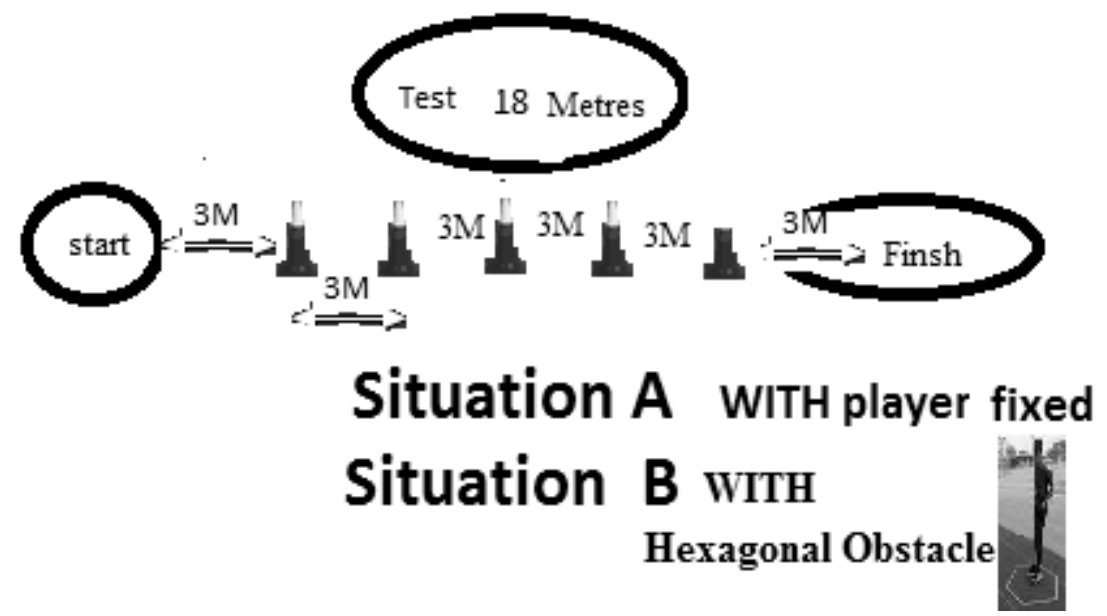

Figure 1. Present protocol of agility test used

\section{MATERIAL and METHODS}

\section{Research Model}

Our goal of this experiment is to test the complexity of agility (physical and cognitive). Indicate in similar as an adaptive and functioning in dynamic environments, enabled through meta-cognitive awareness, which in turn can be enhanced through instruction, according to O'Neil, Perez, \&Baker, (2014). The case of our protocol aimed to examine the player's ability to coordinate his movements in real time compared to changes imposed in traditional test environment. From the background, which concluded that, the reactive element should be included in agility training, testing and research, according to Young, Dawson \& Henry, (2015). Supported by János, József 
\& Levente, (2016) in the importance of cognitive factors in reactive agility performance and suggest that specific methods may be required for training and testing reactive agility and change of direction speed.

\section{Research Group}

Thirty élite male Soccer Players (age: $21.1 \pm 3$ years; body height: $1.76 \pm 4.4$ $\mathrm{m}$; body mass: $74.2 \pm 4.2 \mathrm{~kg}$; body fat: $11.2 \pm 2.2 \%$; years of experience: $7.8 \pm 2.33$ ) volunteered to participate in this study. Tested during the regional selection league of Oran Teams. Selected by attentional means based on their performance in $5-10-5$ shuttle test ( under $_{=} 15.02$, their mean $_{=} 14.64 \pm 0.31$ ) categories excellent class, according to standards developed by the National Strength and Conditioning Association (NSCA, 2018).

\section{Data Collection}

\section{Design}

Laboratory OPAPS approved the study protocol and methods. University of Mostaganem and all subjects gave written informed consent prior to participation. A repeated-measures design was used to collect performance data.

\section{Testing Protocol}

Firstly, we removed the ball from the test to avoid its impact on the validity test. Secondly, we based on 18-meter test with five delimiters spaced by 3 meters between them, proposed in two situations. Situation (A), we refer to traditional agility tests, in which, we change the cone with flex players. The opposite of situation (B) as a new protocol, which include the Hexagonal Obstacle Test protocol as dynamic task for five players, asked to jump in four directions (left- center -/ right- center -front- center -back) into a single rhythm, coordinated by the examiner (See Figure. 1).

\section{Data Analyses}

Data analysis was performed using SPSS 20.0 for Windows (Chicago IL). Data obtained from the tests showed a normal distribution and were presented as mean \pm standard deviation. A paired sample t-test follow by independent Samples test was conducted to combine the results obtained from the two situations (A and B). Pearson correlations (r) set at $\mathrm{p} \leq 0.01$ analyzed the relationship between players performances in the agility test proposed. Their validity was controlled by 5-10-5 shuttle test. As well as homogeneity of the two situations studies calculated by Levene's test. 


\section{RESULTS}

This comparative study based on 18-meter test with five delimiters spaced by 3 meters between them, proposed in two situations. Situation (A) refer to traditional agility tests, situation (B) used the Hexagonal Obstacle Test as mobile tasks in Situation (A), see Fig 1. From table 1. All participants are categories in excellent class, sited in less than $<15.2$, according to Illinois Agility Test Norms 5-0-5 referential to Dawes \& Roozen (2012).

Table 1. Shows the descriptive statistics based on tests practiced in the actual study

\begin{tabular}{lccc}
\hline & Mean & Std. Deviation & N \\
\hline Illinois test & 14.64 & 0.31 & 30 \\
Situation A & 4.80 & 0.18 & 30 \\
Situation B & 7.55 & 0.16 & 30 \\
\hline
\end{tabular}

Based on the correlation calculate between the agility tests used in the present study. Our results show strongest significant positive relationships between the proposed tests agreeing to validation of Illinois Agility Test. Supported by Kutlu, Yapici \& Yilmaz (2017) in their significant value for assessing the integrative agility and skill capability of soccer players.

Table 2. Shows the correlations between the agility tests used in the present study

\begin{tabular}{lcccc}
\hline Variables & & Illinois test & FIX & MOBILLE \\
\hline Illinois test & $\mathrm{r}$ & 1 & $0.899^{* *}$ & $0.848^{* *}$ \\
Situation A & $\mathrm{r}$ & $0.899^{* *}$ & 1 & $0.943^{* *}$ \\
Situation B & $\mathrm{r}$ & $0.848^{* *}$ & $0.943^{* *}$ & 1 \\
& Sig. (2-tailed) & 0.000 & 0.000 & \\
$\quad \mathrm{~N}$ & 30 & 30 & 30 \\
\multicolumn{2}{l}{ **. Correlation is significant at the 0.01 level (2-tailed). } \\
\hline
\end{tabular}

Whereas independent Samples Test and Paired Samples Test are significant between the two situations proposed in the opposite of their homogenous, calculate based on Levene's Test. Confirmed by Veale, Pearce, \& Carlson, et al., (2010) in the importance of reactive component within agility test designs to discriminate athletes' different levels. Supported by our hypothesis in ability of player to coordinate his movements in real time 
compared to the environment variables, case the situation B. Propped by O’Neil, Perez, \& Baker, (2014) as a dynamic environments enabling metacognitive awareness. Recommended by Boichuk et al., (2017) for trainers to focus their attention on qualities, abilities and components of training, which are directly connected with efficiency of game activity.

Table 3. Shows the homogeneity and difference between the two situations proposed

\begin{tabular}{lcccccccc}
\hline \multirow{2}{*}{ Variables } & \multicolumn{3}{c}{ Levene's Test } & \multicolumn{3}{c}{ Independent T-test } & \multicolumn{3}{c}{ Paired T- test } \\
\cline { 2 - 9 } & F & Sig. & t & df & Sig. & t & df & Sig. \\
\hline Situation A vs B & 1.05 & 0.31 & -59.76 & 58 & 0.00 & -2.74 & 29 & 0.00 \\
\hline
\end{tabular}

\section{DISCUSSION and CONCLUSION}

Our aim of this research is to test the complexity of agility (physical and cognitive) away from ball control as a parasitic factor that can alter the results. As much as a real gaming situation to examine the player's ability to coordinate his movements in real time compared to changes in the environment (timing and space). From the background, which concluded that, the reactive element should be incorporated into agility training, testing and research, according to Young, Dawson \& Henry, (2015). Our results show significant differences between the proposed situations (A v's B), in the benefit of situation A. Indicating to author the influence of dynamic environment in the credibility of test of agility case situation B. Confirmed by Sheppard et al., (2006) in the inclusion of anticipation and decisionmaking components through response to the movements of a tester. The case of this study located in situation B Vs A, which suggests that traditional closed skill sprint and sprint with direction change tests may not adequately distinguish between players of different level cognitive functions such as visual processing, Timing, Reaction time Perception, and Anticipation. Reported in similar studies via Top-class football players in playing head up and valuing distance as the strategy to encapsulate their movement in response to a stimulus via this mental skill (Zerf, 2016). Interpret by Piras, Roberto \& Salvatore, 2014 as a qualitative information processed, focusing on the relevant information of tasks aimed at arriving at more accurate predictions. Deduce by Joyce \& Lewindon (2014), as a unique physical attribute that requires multiple types of strength, but also cognitive abilities such as reaction time and decision-making. Sustenance in literature by the ability of players to calculate its decisions according to its cognitive functions such as visual processing, Timing, Reaction time Perception, and Anticipation relative to environmental changes and performance conditions. 
Determined in the present study as factors that influence agility performance as much as appropriate testing protocols and training strategies to assess and improve this quality, according to to Paul, Gabbett \& Nassis, (2016). Claim in similar as mental skills that requires the improvement of reasoning, attention, vigilance, and choice reaction time or information coding under time pressure, according to Marriott (1995) and change of the body position in space (Block, 2007). To sum up, our results are consistent with the view that superiority in situation B proposed as new visual task request from our players to concentrate their attention towards-specific information relevant to players' moves to predict what is likely to happen prior to the event itself. Based on the relevant information, distance, displacement of players, velocity of rhythm imposed by the examiner, as well as appropriate procedures for using these variables to anticipate their paths. Under the background, which agree that this ability is essential to modern football, judge by the speed of the game and the player's decisions, which must generally be done before the action of the opponent. As fundamental factors of anticipation in reading game, include visual abilities and perceptual and cognitive skills. Reported in this study as ability to recall and recognize an evolving pattern to solve the difficulty imposes by the changes related to the requirements imposed in situation $B$. Whereas future research should investigate the factorial validity of the propose protocol, according to Stewart, Turner, \& Miller (2014).

To conclude, our results advance that all tests used in the present study are highly reliable and valid measures of athletics agility as a general athletic ability to change direction. However, athletes regardless their Agility mental skills improvement. Can use our protocol to test their difficulties in dynamic environments, for better concordances of perceptual motor skills to operate simultaneously. Reported in parallel as meta-cognitive awareness, which in turn can be reinforced by cognitive functions such as visual processing, Timing, Reaction time Perception, and Anticipation, as well as change of direction speed. While viewing the limitations of this study, we agree that further studies are required in order to implement the actual findings associated with our hypotheses and protocol.

\section{Acknowledge}

Our protocol test accord to player to read the environment variables, for better concordances as a strategy to improve his Dynamic Decision Making, which include continual decisions each with task-related tradeoffs, founded on its operational cognitive functions communicate based on its visual processing, Timing, Reaction time Perception, and Anticipation as well as change of direction speed. 
Zerf, M. (2018). Agility stimulators and their effects on traditional testing protocols case selected male soccer players. Journal of Sport Sciences Researches, 3(1):64-72.

\section{REFERENCES}

Block, M. E. (2007). A teacher's guide to including students with disabilities in general physical education. Baltimore: Brookes Publishing Company.

Boichuk, R., Iermakov, S., Nosko, M., Kovtsun, V., \& Nosko, Y. (2017). Influence of motor coordination indicators on efficiency of game activity of volleyball players at the stage of specialized basic training. Journal of Physical Education and Sport, 17(4), 2632-2637. Doi:10.7752/jpes.2017.04301.

Dawes, J., \& Roozen, M. (2012). Developing agility and quickness. Canada: Human Kinetics.

Goral, K. (2015). Examination of agility performances of soccer players according to their playing positions. The Sport Journal, 2015, 1. doi:10.17682/sportjournal/2015.004

Joyce, D., \& Lewindon, D. (2014). High-Performance Training for Sports. Caanda: Human Kinetics.

Kutlu, M., Yapici, H., \& Yilmaz, A. (2017). Reliability and validity of a new test of agility and skill for female amateur soccer players. Journal of human kinetics, 56(1), 219227. Doi:10.1515/hukin-2017-0039.

Marriott, B. M. (1995). Not eating enough: Overcoming underconsumption of military operational rations. US: National Academies.

Matlák, J., Tihanyi, J., \& Rácz, L. (2016). Relationship between reactive agility and change of direction speed in amateur soccer players. The Journal of Strength \& Conditioning Research, 30(6), 1547-1552. Doi: 10.1519/JSC.0000000000001262.

NSCA Kinetic Select, \& Brown, L.E. (2018). Assessing Agility Using the T Test, 5-10-5 Shuttle, and Illinois Test. Retrieved from NSCA Store: https://www.nsca.com/education/articles/assessing_agility_using_testing/.

O'Neil, H. F., Perez, R. S., \& Baker, E. L. (2014). Teaching and measuring cognitive readiness. New York, NY: Springer.

Paul, D. J., Gabbett, T. J., \& Nassis, G. P. (2016). Agility in team sports: Testing, training and factors affecting performance. Sports Medicine, 46(3), 421-442. https://doi.org/10.1007/s40279-015-0428-2.

Piras, A., Roberto, L., \& Salvatore, S. (2014). Response time, visual search strategy, and anticipatory skills in volleyball players. Journal of Ophthalmology, 2014, 1-10. doi:10.1155/2014/189268

Porcari, J., Bryant, C., \& Comana, F. (2015). Exercise physiology. Philadelphia: Davis Company.

Sheppard, J. M., Young, W. B., Doyle, T. L. A., Sheppard, T. A., \& Newton, R. U. (2006). An evaluation of a new test of reactive agility and its relationship to sprint speed and change of direction speed. Journal of science and medicine in sport, 9(4), 342-349. Doi: $10.1016 /$ j.jsams.2006.05.019. 
Zerf, M. (2018). Agility stimulators and their effects on traditional testing protocols case selected male soccer players. Journal of Sport Sciences Researches, 3(1):64-72.

Stewart, P. F., Turner, A. N., \& Miller, S. C. (2014). Reliability, factorial validity, and interrelationships of five commonly used change of direction speed tests. Scandinavian journal of medicine \& science in sports, 24(3), 500-506. Doi: https://doi.org/10.1111/sms.12019

Tanner, R., \& Gore, C. (2012). Physiological tests for elite athletes. 2nd edition. Australian: Human Kinetics.

Veale, J. P., Pearce, A. J., \& Carlson, J. S. (2010). Reliability and validity of a reactive agility test for Australian football. International Journal of Sports Physiology and Performance, 5(2), 239-248.

Young, W. B., Dawson, B., \& Henry, G. J. (2015). Agility and change-of-direction speed are independent skills: Implications for training for agility in invasion sports. International Journal of Sports Science \& Coaching, 10(1), 159-169. doi:doi.org/10.1260/1747-9541.10.1.159.

Zerf, M. (2016). Which visual sight skill tested and developed the interaction between central and peripheral vision case duels dribbling soccer skills. International Journal of Applied Exercise Physiology, 5(3), 31-37. doi:https://doi.org/10.22631/ijaep.v5i3.79. 